\title{
Novel hydrocarbon monooxygenase genes in the metatranscriptome of a natural deep-sea hydrocarbon plume
}

\author{
Meng Li, ${ }^{1}$ Sunit Jain, ${ }^{1}$ Brett J. Baker, ${ }^{1}$ Chris Taylor ${ }^{1}$ \\ and Gregory J. Dick ${ }^{1,2,3 *}$ \\ Departments of ${ }^{1}$ Earth and Environmental Sciences and \\ ${ }^{2}$ Ecology and Evolutionary Biology, ${ }^{3}$ Center for \\ Computational Medicine and Bioinformatics, University \\ of Michigan, Ann Arbor, MI, USA.
}

\section{Summary}

Particulate membrane-associated hydrocarbon monooxygenases (pHMOs) are critical components of the aerobic degradation pathway for low molecular weight hydrocarbons, including the potent greenhouse gas methane. Here, we analysed pHMO gene diversity in metagenomes and metatranscriptomes of hydrocarbon-rich hydrothermal plumes in the Guaymas Basin (GB) and nearby background waters in the deep Gulf of California. Seven distinct phylogenetic groups of pHMO were present and transcriptionally active in both plume and background waters, including several that are undetectable with currently available polymerase chain reaction (PCR) primers. The seven groups of pHMOs included those related to a putative ethane oxidizing Methylococcaceae-like group, a group of the SAR324 Deltaproteobacteria, three deep-sea clades (Deep sea-1/symbiont-like, Deep sea-2/PS-80 and Deep sea-3/OPU3) within gammaproteobacterial methanotrophs, one clade related to Group $Z$ and one unknown group. Differential abundance of pHMO gene transcripts in plume and background suggests niche differentiation between groups. Corresponding 16S rRNA genes reflected similar phylogenetic and transcriptomic abundance trends. The novelty of transcriptionally active pHMOs we recovered from a hydrocarbon-rich hydrothermal plume suggests there are significant gaps in our knowledge of the diversity and function of these enzymes in the environment.

Received 2 October, 2012; revised 10 May, 2013; accepted 3 June, 2013. *For correspondence. E-mail gdick@umich.edu; Tel. 1-734763-3228; Fax 1-734 7634690.
Introduction

The copper-containing membrane-bound monooxygenases (CuMMO) are a large family of environmentally important enzymes that mediate the biogeochemical cycling of carbon and nitrogen. The most notable of these are particulate methane monooxygenase (pMMO) and ammonia monooxygenase (AMO). While CuMMOs are widely distributed across phyla Alpha, Beta and Gammaproteobacteria (Hanson and Hanson, 1996; Dunfield et al., 2002; Stoecker et al., 2006; Arp et al., 2007; Baani and Liesack, 2008; Chen et al., 2010), Verrucomicrobia (Dunfield et al., 2007; Pol et al., 2007), NC10 (Ettwig et al., 2010) and Thaumarchaea (Könneke et al., 2005; Tourna et al., 2011), their functions are generally restricted to oxidation of methane (catalysed by pMMO) and ammonia (catalysed by AMO). However, the recent discovery of novel membrane-associated, copper containing, hydrocarbon monooxygenases (pHMOs) expands the known functional diversity of the CuMMO protein family (Sayavedra-Soto et al., 2011; Coleman et al., 2012). Redmond and colleagues (2010) found that ${ }^{13} \mathrm{C}$-labeled ethane was incorporated into biomass [(deoxyribonucleic acid) DNA] by a group of Methylococcaceae with a novel pMMO, suggesting these enzymes may be involved in ethane utilization. Recognition of divergent CuMMO-like coding genes in the genomes of bacterial isolates further highlights the major challenges in relating CuMMO diversity and function (Balasubramanian et al., 2010; Sayavedra-Soto et al., 2011; Tavormina et al., 2011; Coleman et al., 2012; Mason et al., 2012).

Evidence of substrate diversity of the CuMMO was first identified in two butane-oxidizing Actinobacteria, Nocardioides sp. CF8 and Mycobacterium sp. JOB5 (Hamamura et al., 1999; 2001; Hamamura and Arp, 2000). Subsequently, expression of genes encoding a three-component membrane-associated monooxygenase with sequence homology to CuMMO correlated with butane utilization by Nocardioides sp. CF8 (Sayavedra-Soto et al., 2011). Similarly, novel CuMMOs capable of oxidizing $\mathrm{C}_{2}-\mathrm{C}_{4}$ alkanes were identified in two strains of Mycobacteria, which like Nocardioides, are also members of the Actinomycetales (Coleman et al., 2011; 
2012). Furthermore, novel pMMO-like sequences have been identified in recently sequenced genomes, including gammaproteobacterial methanotrophs (Tavormina et al., 2011), two marine ethylene-assimilating Haliea spp. (Suzuki et al., 2012), Nocardioides Broad-1 (ZP_08197402) and SAR324 Deltaproteobacteria (Swan et al., 2011). Thus, it is apparent that CuMMOs can oxidize not only ammonia or methane but also short chain hydrocarbons, suggesting the sequence divergence within this protein family may reflect novel biochemical and physiological roles within the cell.

The role of PMMO/AMO enzymes in methane and ammonia oxidation has been well established, and genes encoding subunit $A(P m o A / A m o A)$ are commonly used as functional biomarkers for surveying aerobic methane and ammonia oxidizers in nature (Hanson and Hanson, 1996; Costello and Lidstrom, 1999; Norton et al., 2002; Inagaki et al., 2004; Francis et al., 2005; McDonald et al., 2008; Chistoserdova, 2011; Lüke and Frenzel, 2011). However, little is known of the distribution and diversity of CuMMOs responsible for the oxidation of short chain hydrocarbons especially in hydrocarbon-rich environments, which are globally distributed in deep sea, including natural methane and hydrocarbon seeps (Milkov et al., 2003; Campbell, 2006), hydrothermal vents (Beaulieu, 2010) and oil spills such as the Deepwater Horizon (Valentine et al., 2010). These hydrocarbon seeps substantially contribute to the deep-sea carbon pool and have been postulated to maintain populations of low molecular weight hydrocarbon-degrading bacteria (Baelum et al., 2012; Muyzer and van der Kraan, 2008; Mason et al., 2012; Valentine, 2010; Valentine, 2011).

Guaymas Basin (GB) is a sediment-hosted hydrothermal system within a semi-enclosed basin in the central Gulf of California. Guaymas Basin hydrothermal plumes are chemically distinct from typical mid-ocean ridges because hydrothermal fluids interact with sediments as they ascend to the seafloor (Vondamm et al., 1985). These plumes are enriched in potential microbial energy sources, such as ammonium, methane and other gaseous hydrocarbons (Welhan and Lupton, 1987; Lam, 2004; Dick et al., 2009; Dick and Tebo, 2010). It has been estimated that methane concentration could reach up to $54 \mathrm{mM}$ in vent fluids and more than $31.6 \mu \mathrm{M}$ in the plumes, while $\mathrm{C}_{2}-\mathrm{C}_{4}$ alkanes concentrations range from $1.4 \mu \mathrm{M}\left(n-\mathrm{C}_{4} \mathrm{H}_{10}\right)$ to $444 \mu \mathrm{M}\left(\mathrm{C}_{2} \mathrm{H}_{6}\right)$ in the fluids (Welhan and Lupton, 1987; Lam, 2004; McCollom, 2008). Previous studies of microbial methane oxidation at GB have focused primarily on warm, anoxic sediments (Teske et al., 2002; Biddle et al., 2011), however methanotrophy is also a dominant metabolism in the cold, oxic water column (Lesniewski et al., 2012). Here, we present a detailed analysis of pHMOs in the GB metagenomes and metatranscriptomes and find that seven different phylogenetically diverse pHMOs are simultaneously transcriptionally active in both of hydrothermal plume and background waters.

\section{Results and discussion}

Presence of pHMO genes in metagenomic and metatranscriptomic datasets

To investigate the diversity of active membraneassociated pHMOs in natural deep-sea hydrocarbon plumes, we analysed shotgun sequenced community DNA and complementary DNA (cDNA) from four hydrothermal plume samples and two background samples retrieved from the deep Gulf of California on three different cruises (Table S1). A total of 102631 pHMO related DNA and cDNA sequence reads and up to 40 unique contigs were identified in metagenomes and metatranscriptomes of GB hydrothermal plumes and background samples. In each instance, there was a greater percentage of total metagenome derived reads belonging to genes encoding $A, B$ and $C$ subunits of pHMOs in the plumes than in background (Table 1), whereas only the $A$ and $B$ subunits had higher percentages of cDNA reads in plumes compared to background (Table 1). An extra gene copy of pmoC is present in the genome of Methylococcus capsulatus (Bath) (Stolyar et al., 1999), but the near-stoichiometric recovery of genes for the three subunits suggests this not the case for GB populations. Our data are more consistent with differential expression of genes for different $\mathrm{pHMO}$ subunits as has been observed in a verrucomicrobial methanotroph (Erikstad et al., 2012). Interestingly, a divergent C subunit of AMO in Nitrosomonas europaea (homologous to pmoC) has been implicated in stress response (Berube and Stahl, 2012). By analogy, the disproportionate subunit C expression we observe (especially in background, where substrate concentrations are lower) may reflect an equivalent stress response, albeit by differential expression rather than extra gene copies. No genes encoding soluble methane monooxygenase (sMMO) or soluble butane monooxygenase (sBMO) were identified in any of the GB metagenomic and metatrascriptomic datasets. This suggests that gaseous hydrocarbon oxidation in the deep Gulf of California, including hydrocarbon-enriched hydrothermal plumes, is dominated by pHMO-mediated oxidation.

\section{Phylogenetic analysis of pHMOs and comparison to $16 S$ rRNA phylogeny}

Phylogenetic analyses of genes for $\mathrm{pHMO}$ subunit $\mathrm{A}$ revealed seven distinct clusters, including pMMOs of 
Deep sea-1/symbiont-like, Deep sea-2/PS-80 and Deep sea-3/OPU3 groups (Lüke and Frenzel, 2011), pHMOs affiliated with putative ethane oxidizing Methylococcaceae-like bacteria (Redmond et al., 2010), a group closely related to SAR324 Deltaproteobacteria (Swan et al., 2011), and two groups, Group $Z$ (Tavormina et al., 2010) and Unknown group, of unknown function (Fig. 1A). Similar phylogenetic groups and relationships of pHMOs were also obtained from respective $B$ and $C$ subunits (Figs S1 and S2) and from related $16 \mathrm{~S}$ ribosomal ribonucleic acid (rRNA) genes (Fig. 1B). Thus, at least seven distinct phylogenetic pHMO groups are present and transcriptionally active in the GB hydrothermal plume. Five of the groups are related to previously reported sequences that have been implicated in the oxidation of $\mathrm{C}_{1}$ to $\mathrm{C}_{4}$ alkanes. Comparative analysis of active sites/ metal centres strongly support these pHMOs belong to the CUMMO superfamily, sharing relatively conserved amino acids at the Cu-binding sites (Fig. S3). Although Mason and colleagues (2012) also noted a diversity of pmo sequences expressed in plumes of the Deepwater Horizon oil spill, we believe that our study is the first detailed report of concurrent abundant transcription of multiple phylogenetically distinct $\mathrm{pHMO}$ genes in a single environment.

Three groups of pHMO sequences (Deep sea-1/2/3) share high amino acid sequence identity with environmental sequences but have relatively low sequence identity to those from pure cultures (Table S2). All three of these pMMOs belong to gammaproteobacterial methanotrophs, consistent with the dominance of gammaproteobacterial methanotrophs in hydrothermal systems (Elsaied et al., 2004; Wasmund et al., 2009; Crépeau et al., 2011). Interestingly, the Deep sea-2/PS-80 and Deep sea-3/OPU3 pMMOs share high similarity (95$100 \%$ amino acid sequence identity) to sequences retrieved from the Deepwater Horizon oil spill in the Gulf of Mexico (Kessler et al., 2011), the Santa Monica Basin methane seep (Tavormina et al., 2008; 2010; Redmond et al., 2010) and the North Fiji hydrothermal vent field (Tavormina et al., 2010), indicating that these genes are widely distributed in pelagic water column environments. One pMMO group, referred to here as 'Deep sea-1/ symbiont-like', is most closely related to sequences from the water column of the Eastern Pacific Ocean oxygen minimum zone (OMZ) (Hayashi et al., 2007), sediments from a methane seep (Redmond et al., 2010), and endosymbionts of the hydrothermal vent mussel Bathymodiolus azoricus (Spiridonova et al., 2006). To date, the Deep sea-1/symbiont-like pMMO clone has only been reported once from water column samples $(282 \mathrm{~m}$ and $497 \mathrm{~m}$ below surface; referred to as OPU2 in their study) by Hayashi and colleagues (2007). Thus, our result is the first demonstration of the significant presence and 


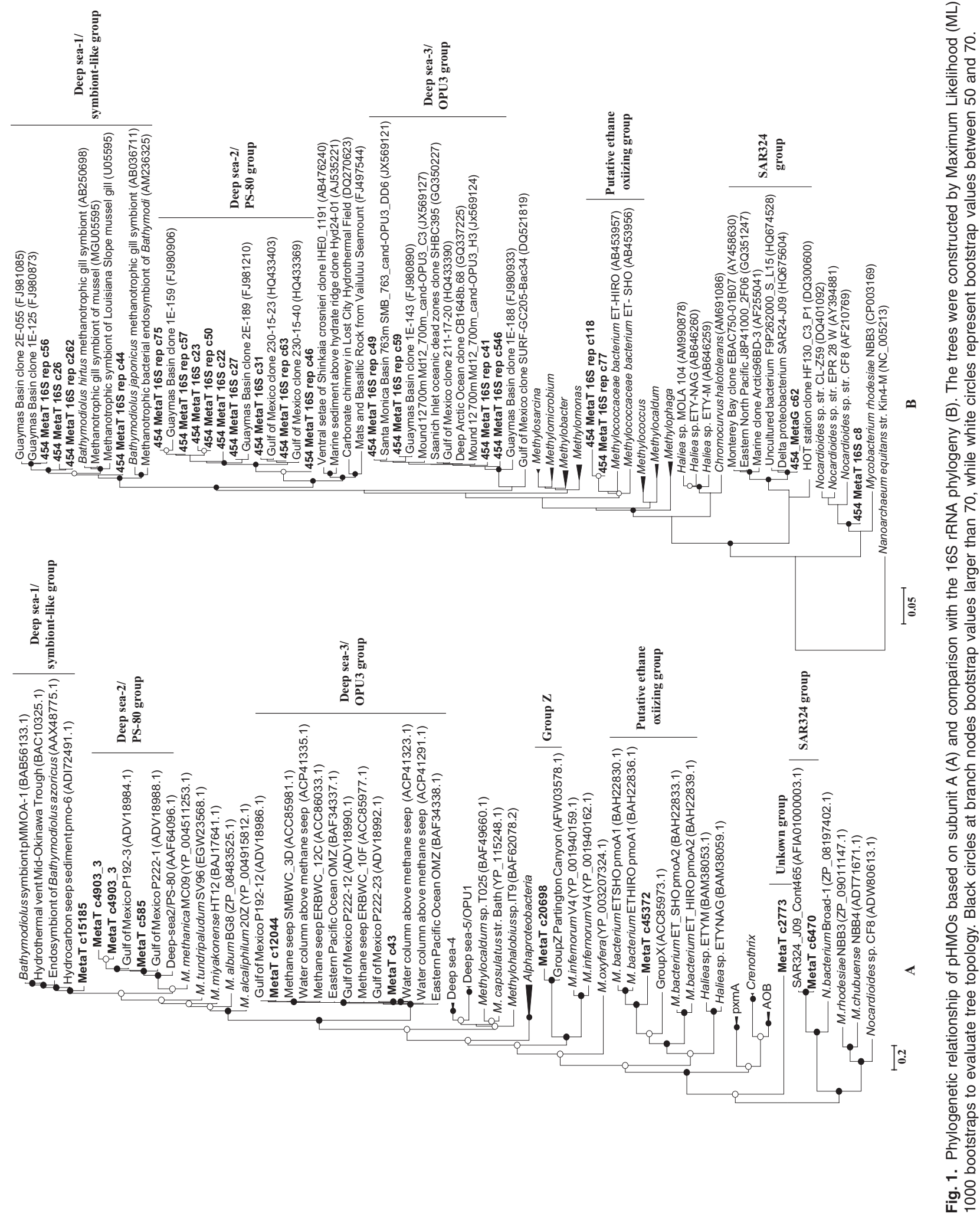


transcriptional activity of Deep sea-1/symbiont-like pMMOs in the deep water column (see below).

Two novel groups of $\mathrm{GB}$ pHMO sequences were phylogenetically affiliated with proteins for oxidation of $\mathrm{C}_{2}-\mathrm{C}_{4}$ alkanes. First, the putative ethane-oxidizing cluster has relatively low similarity to any pMMO from methanotrophs $(<50 \%)$ but up to $70.2 \%$ sequence identity to pHMOs from two putative ethane-oxidizing Methylococcaceae-like species (Table S2). 16S rRNA genes with high sequence identity $(94 \%-96 \%)$ to these of two putative ethane-oxidizing Methylococcaceae-like species were also recovered from metatranscriptome (Fig. 1B), indicating the presence of transcriptionally active putative ethane-oxidizing Methylococcaceae-like bacteria. Second, the putative $\mathrm{C}_{2}-\mathrm{C}_{4}$ alkane-oxidizing group contains novel GB pHMO sequences that share $93.6 \%$ to $98.2 \%$ protein sequence identity to the three subunits of pHMO recently identified in the single-cell amplified genome of SAR324_J09 (Swan et al., 2011) (Table S2 and Fig. 1A). SAR324 is an ubiquitous group of uncultured Deltaproteobacteria recently proposed to be capable of $\mathrm{C}_{1}$ metabolism based on the presence of the pHMO operon in the genome of SAR324_J09 (Swan et al., 2011). SAR324 is one of the most abundant microbial groups in the GB plumes (Dick and Tebo, 2010; Lesniewski et al., 2012), and its 16S rRNA genes show high similarity (99\%) to SAR324_J09 (Fig. 1B). Our phylogenetic analysis shows that both pHMOs from SAR324_J09 and those recovered from GB are most closely related to those of Actinomycetes, Mycobacterium chubuense NNB4 and Nocardioides sp. CF8 (Fig. $1 \mathrm{~A}$ ), which are capable of $\mathrm{C}_{2}-\mathrm{C}_{4}$ alkane degradation (Sayavedra-Soto et al., 2011; Coleman et al., 2012). Furthermore, our parallel investigation on the metagenome and metatranscriptome of GB-SAR324 indicates that this group also contains and expresses the necessary metabolic pathways for $\mathrm{C}_{2}-\mathrm{C}_{4}$ alcohol utilization (Sheik et al., 2013), suggesting that the GB population utilizes $\mathrm{C}_{2}-\mathrm{C}_{4}$ alkanes rather than methane. However, it should be noted that the sequence similarity between SAR324 pHMO and these of $\mathrm{C}_{2}-\mathrm{C}_{4}$ alkaneoxidizing bacteria (Mycobacterium chubuense NNB4 and Nocardioides sp. CF) is relatively low $(<43 \%)$, thus further experimental data are needed to confirm the actual substrate specificity of these enzymes. Nevertheless, our results constitute the first environmental detection of high transcription levels (see below) for this group of enzymes, further emphasizing the previously unrecognized role of SAR324 cluster in the oxidation of hydrocarbons in the oceans.

Given the novelty of pHMOs at GB, we compared our sequences to PCR primers commonly used for $\mathrm{pHMO}$ detection. The Deep sea-3/OPU3 pHMOs are perfect matches for pmoA189f-pmoAwc377r and pmoC346f-
pmoAwc377r (Costello and Lidstrom, 1999; Tavormina et al., 2008; 2010), and the Deep sea-1/symbiont-like and Deep sea-2/PS-80 pHMOs are perfect matches for primer set pmoA189f-mb661r (Costello and Lidstrom, 1999). However, no combination of currently available primer sets perfectly matches the GB pHMO sequences related to putative ethane oxidizing and SAR324 groups. This result suggests that much of the natural community diversity may be missed using a traditional PCR-based approach and highlights the utility of random shotgun sequencing in surveying natural communities (Gilbert et al., 2008; Gilbert and Dupont, 2011).

Another dimension of pHMO diversity, the microdiversity within populations, was revealed by the deep sequence coverage provided by Illumina metatranscriptomic sequencing. Two metatranscriptomic contigs (contig_43 and contig_585) related to Deep sea-2/PS-80 and Deep sea-3/OPU3 pMMOs displayed variable sequences for each group within the deep-sea populations respectively. These variable sequences were on average $99.2 \%$ similar to each other at the nucleotide level. The variable nucleotide positions were observed in the $p m o C$ and $p m o B$ for contig_43 and $p m o A$ and $p m o B$ in contig_585 (Fig. S4). These nucleotide substitutions resulted in changes in amino acid sequences but did not occur at metal centre sites that are critical for function (Lieberman and Rosenzweig, 2005; Balasubramanian et al., 2010) (Fig. S3). Since genomic context for each of these variable sequences is unavailable, it is impossible to determine if they belong to different species/strains or are gene duplicates within a single genome (Ward et al., 2004; Hou et al., 2008; Boden et al., 2011; Stein et al., 2011; Svenning et al., 2011). Regardless, the presence of closely related sequence types within each pMMO group further underscores the multidimensional diversity of pHMOs in the GB hydrothermal system.

\section{Transcriptional activity and distribution of different groups}

To assess the transcriptional activity and distribution of pHMOs, we mapped cDNA reads to the different $\mathrm{pHMO}$ groups in plume and background samples. pHMO-coding genes from Deep sea1/symbiont-like, Deep sea-2/PS-80 and putative $\mathrm{C}_{2}-\mathrm{C}_{4}$ alkane-oxidizing (SAR324) group account for a greater portion of metatranscriptomic reads in plume than in background (Fig. 2 and Fig. S5). In contrast, Deep sea-3/OPU3 and putative ethane oxidizing groups have similar or even higher relative abundance of transcripts in background samples. This suggests that pHMOs of Deep sea-2/PS-80, Deep sea1/symbiont-like and SAR324 group are more responsive to increased concentrations of hydrocarbons in plumes, whereas the Deep sea-3/OPU3 and putative ethane oxidizing groups 


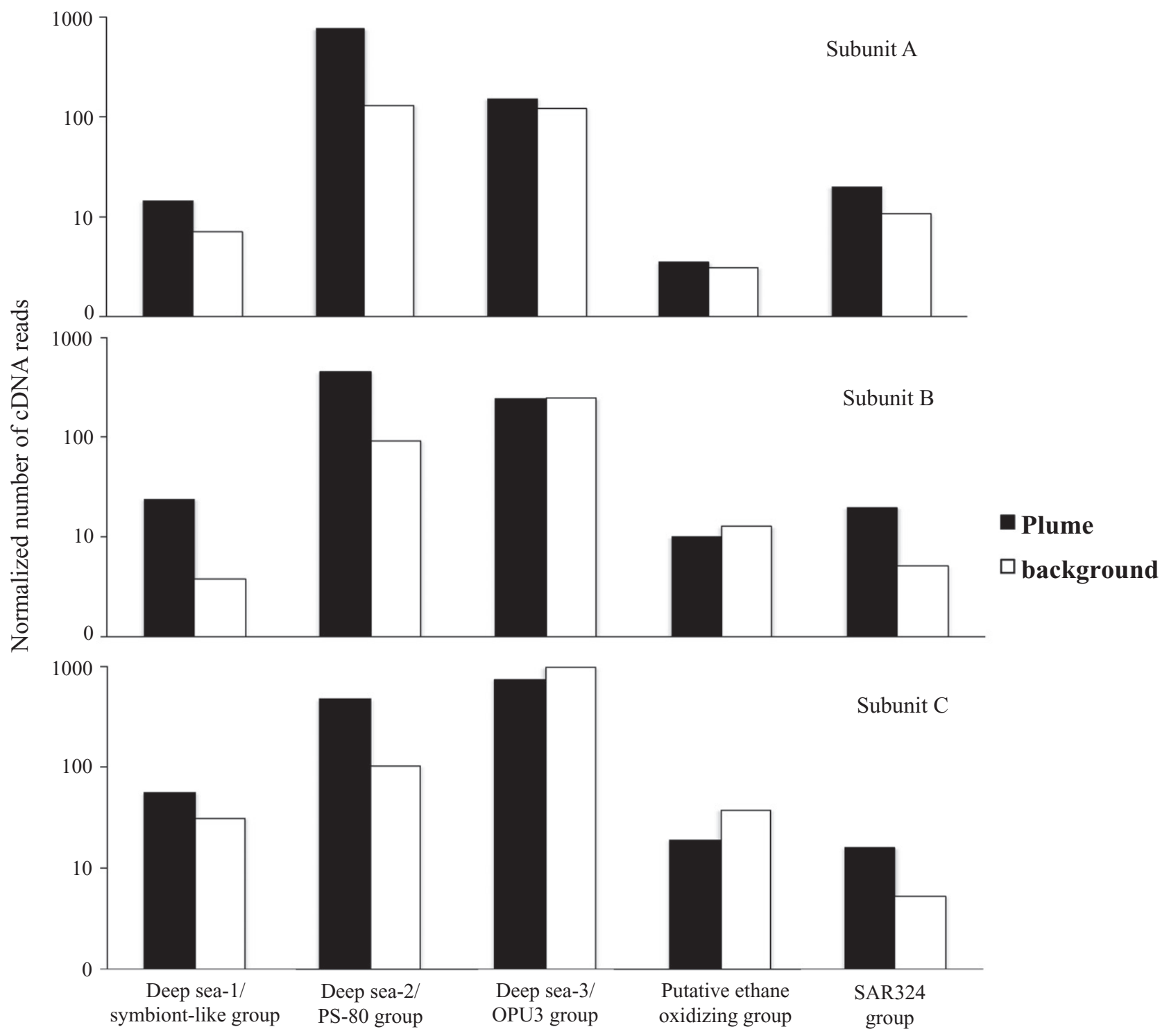

Fig. 2. Relative abundance of transcripts (Illumina) for genes encoding three subunits of different groups of pHMOs from plume and background samples. Transcript abundance is normalized to the length of gene and total number of transcript reads from each sample.

may have higher affinity for low substrate concentrations. Consistent with this conclusion, lack of correlation of Deep sea-3/OPU3 abundance with methane has been previously interpreted as evidence for adaptation of this group to low methane concentration (Tavormina et al., 2013). Interestingly, OPU1 and Deep sea-3/OPU3 were previously observed to largely occur together (Tavormina et al., 2008; 2010; 2013), but OPU1 is conspicuously missing from the GB dataset. Differences in the relative abundance of these two groups correlate with reduced $\mathrm{O}_{2}$ concentrations and depth within the Costa Rica OMZ (Tavormina et al., 2013), where OPU3 is more abundant in the low $\mathrm{O}_{2}$ zone $\left(\sim 5.80 \mu \mathrm{M} \mathrm{O}_{2}\right)$ at $200-650 \mathrm{~m}$, while
OPU1 dominates in deeper water (below $\sim 700 \mathrm{~m}$ ) with higher $\mathrm{O}_{2}$ concentration $\left(\sim 17.8 \mu \mathrm{M} \mathrm{O}_{2}\right)$. Our samples all have higher $\mathrm{O}_{2}$ concentrations $\left(26-28 \mu \mathrm{M} \mathrm{O} \mathrm{O}_{2}\right.$ in $\mathrm{GB}$, $46 \mu \mathrm{M} \mathrm{O}_{2}$ in Carmen Basin), so other environmental factors might also be involved in controlling the distribution of OPU1 and OPU3.

Similar trends of transcript abundance were apparent in 16S rRNA genes, where transcripts from Deep sea-2/ PS-80 and Deep sea-1/symbiont-like methanotrophs are much more abundant in plume than background (Fig. S6). Methane concentrations in buoyant and neutrally buoyant GB plumes can reach up to 31.6 and $11.2 \mu \mathrm{M}$ respectively, while concentrations in the overlying water are only 
16-65 nM (Lam, 2004). Differential abundance of transcripts from 16S rRNA and corresponding pHMO genes between the background and the plume may be indicative of niche differentiation between different groups. Furthermore, it should also be noted that all of the methanotrophic genes and groups we report here to be operating under dysoxic conditions and a relatively narrow range of cold temperatures are distinct from those of hydrothermal sediments at GB, where anaerobic methane oxidation is carried out by archaea under anoxia and a much higher and wider temperature range (15 to $95^{\circ} \mathrm{C}$ ) (Teske et al., 2002; Biddle et al., 2011).

To assess the broader distribution of these novel pHMOs, we used subunit $A$ sequences of each group to query data from diverse marine environments (Tables S3 and S4). We found that $p m o A$ sequences from the Deep sea-1/symbiont-like group are often present in association with hydrothermal vent fauna, mats and deposits (Elsaied et al., 2004; Spiridonova et al., 2006; Duperron et al., 2007; Zbinden et al., 2008; Crépeau et al., 2011; Raggi et al., 2012) or sediments of methane seeps (Yan et al., 2006; Redmond et al., 2010) but only rarely in the water column. In contrast, pmoA related to Deep sea-2/ PS-80 and Deep sea-3/OPU3-like groups are widely distributed in diverse environments, including sediments and water column of methane seeps (Inagaki et al., 2004; Tavormina et al., 2008; 2010; Reed et al., 2009; Wasmund et al., 2009; Redmond et al., 2010; Havelsrud et al., 2011), hydrothermal vent systems (Nercessian et al., 2005; Reed et al., 2009; Tavormina et al., 2010; Crépeau et al., 2011) and other pelagic marine environments (Hayashi et al., 2007; Tavormina et al., 2010; 2013). We identified sequences ( $>60 \%$ amino acid similarity) similar to $\mathrm{pHMO}$ of putative ethane oxidizing bacteria and putative $\mathrm{C}_{2}-\mathrm{C}_{4}$ alkane-oxidizing bacteria (SAR324) in metatranscriptomes of water column samples from the Deepwater Horizon at Gulf of Mexico (Table S4), supporting the potential participation of these enzymes in hydrocarbon oxidation. In addition, related sequences of the SAR324 pHMO were also identified from OMZs of Eastern Tropical South Pacific Ocean and Eastern Subtropical North Pacific Ocean, as well as water column samples from two profiles of HOT station at $500 \mathrm{~m}$ (Table S4), indicating a broad distribution of SAR324-like pHMOs in diverse marine environments. Furthermore, related sequences to the two unknown functional pHMO groups (Group $\mathrm{Z}$ and Unknown group) were recovered from deep-sea hydrocarbon-enriched environments, such as Partington Canyon (Tavormina et al., 2010) and the Deepwater Horizon oil spill in Gulf of Mexico (Tables S3 and S4). Future studies are required to definitively link this genetic potential to actual quantitative contributions and rates of hydrocarbon oxidation in the deep sea.

\section{Conclusions}

In this study, we found an array of diverse and novel pHMO genes in the community genomes and transcriptomes of a natural deep-sea hydrocarbon-rich hydrothermal plume and surrounding background waters in the Gulf of California. In addition to genes of known methanotrophs that are widely distributed yet uncultivated, these pHMOs affiliate with recently discovered putative $\mathrm{C}_{2}-\mathrm{C}_{4}$ alkane-oxidizing enzymes that have not previously been described in any detail in marine systems. Particularly intriguing is the potential for a significant yet previously unrecognized role of versatile SAR324 bacteria in the oxidation of hydrocarbons in the marine environment. More broadly, these results underscore the power of metagenomics and metatranscriptomics for identification of genetic and functional diversity present in natural microbial communities. In practical terms, the prevalence of novel pHMO genes that are undetectable by current primers highlights the persisting limitations of traditional PCR-based approaches for tackling the staggering diversity of natural microbial communities. While lack of cultured representatives continues to hinder our understanding of the biochemical and physiological underpinnings of this diversity, cultivationindependent approaches can elucidate the ecology of these organisms by defining how they vary in space and time as a function of environmental parameters.

Although the diversity of pHMOs is increasingly well recognized, this study is the first to demonstrate simultaneous transcriptional activity of multiple phylogenetically distinct pHMOs rather than spatial and/or temporal separation of activity. This co-occurrence of multiple transcriptionally active $\mathrm{pHMO}$ genes and variants within deep-sea microbial communities and populations likely reflects intense competition and suggests extensive resource partitioning during microbially mediated alkane oxidation. Given the ubiquity of alkanes (van Beilen et al., 2003; van Beilen and Funhoff, 2007) and the environmental costs of oil spills, future studies must address these dynamics and the relationship between pHMO diversity and function in natural environments if we are to understand and predict the fate of hydrocarbons released into the oceans.

\section{Experimental procedures}

Sample collection and extraction of nucleic acids. Samples were collected in 2004 and 2005 aboard the R/V New Horizon as described previously (Dick et al., 2009; Dick and Tebo, 2010). Briefly, samples were collected in Niskin bottles by CTD-rosette and kept under in situ conditions (cold and dark) until processing. Immediately upon shipboard retrieval, samples were pressure filtered with $\mathrm{N}_{2}$ gas onto $0.2 \mu \mathrm{m}$ pore size polycarbonate filters, which were immediately preserved in RNAlater as instructed by the manufacturer (Ambion). DNA was extracted from filters as described previously (Dick and 
Tebo, 2010). RNA extraction and random RNA amplification and CDNA synthesis were performed as described previously (Frias-Lopez et al., 2008; Shi et al., 2011). Details of the location, sampling date, environmental conditions and concentration of nucleic acids of each sample are provided in Table S1.

DNA sequencing, de novo assembly and annotation. Purified total genomic DNA and cDNA (no rRNA removal was conducted) were used to prepare DNA libraries for 454 Titanium pyrosequencing at the Dedicated Marine Microbiology DNA Sequencing Pipeline at Pennsylvania State University according to standard protocols (454 Life Sciences, Roche). In addition, samples plume-4 (GD6) and background-1 (GD7) were used for metatranscriptomic sequencing by Illumina HiSeq 2000 (Illumina) at the University of Michigan DNA Sequencing Core. DNA and cDNA sequence reads obtained from 454 and Illumina sequencing were separately de novo assembled by different strategies. The read sequences obtained from 454 Titanium pyrosequencing were trimmed and quality filtered with the Mothur software package (Schloss et al., 2009, http://www.mothur.org). The trimmed and qualityfiltered short reads were utilized for de novo assembly as described in detail previously (Baker et al., 2012; Lesniewski et al., 2012). For Illumina datasets, cDNA reads were first de-replicated by removing identical reads, then cDNA reads were quality trimmed by Sickle (quality score $>30$, https:// github.com/najoshi/sickle). The de-replication and trimming processes reduced the number CDNA reads from 206 to 45 million in the plume and 245 to 130 million in the background sample. These de-replicated and trimmed cDNA datasets were then assembled by Velvet (1.2.01) and subsequently processed using the transcriptomic assembler Oases 0.2.04 (Zerbino and Birney, 2008; Schulz et al., 2012; Baker et al., 2013, http://www.ebi.ac.uk/ zerbino/oases/). All contigs were submitted to the DOE Joint Genome Institute (JGI) Integrated Microbial Genomes website (https://merced.jgi-psf.org/cgi$\mathrm{bin} / \mathrm{mer} / \mathrm{main} . c g i)$ for gene calling and annotation.

Identification and phylogenetic analysis of pHMO and $16 S$ rRNA genes. Hydrocarbon monooxygenase gene sequences in $\mathrm{GB}$ metagenomes and metatranscriptomes were identified using BLASTX searches (bit score $>50$ ) against methane/ammonia monooxygenase sequences in National Center for Biotechnology Information (NCBI) (http:// www.ncbi.nlm.nih.gov/) and Functional Gene Database (http://fungene.cme.msu.edu). To confirm that they were indeed most closely related to genes encoding $\mathrm{pHMO}$, candidate putative $\mathrm{pHMO}$ genes were then used as queries against the non-redundant database at $\mathrm{NCBI}$, as well as against custom databases of manually identified and curated genes. For sequences that passed this test, affiliations with contigs were determined, and respective contigs were analysed. Each pHMO-related contig was manually analysed via BLASTP analysis of predicted proteins against the non-redundant database to determine degree of similarity to known sequences. Full length of ammonia/methane monooxygenase subunit $A$ open reading frames (ORFs) were extracted from the operons with BLASTX and translated into amino acids, then aligned to known related ammonia/methane monooxygenase subunit $A$ sequences using Clustal/omega/1.1.0 (Sievers et al., 2011, http://www.clustal.org/omega/). A high-quality alignment region consisting of 221 amino acids was selected using TrimAl (Capella-Gutierrez et al., 2009). The PhyML mixture was used to generate a maximum likelihood mixture model tree using linkage disequilibrium (LD) model after testing of aligned sequences using ProTest (Abascal et al., 2005). Partial length ammonia/methane monooxygenase subunit $A$ sequences were aligned with 34 full length sequences and placed on the tree with the maximum likelihood placement algorithm in RAxML (Stamatakis, 2006; Berger et al., 2011). The tree of ammonia/methane monooxygenase subunit $B$ and $\mathrm{C}$ was constructed using the same method. To search for $16 \mathrm{~S}$ rRNA gene sequences from the pHMOs bacterial hosts, CDNA reads related to methanotrophs, SAR324 cluster and Actinomycetales from 454 metatranscriptomic dataset were identified by BLASTN (sequence identity $>99 \%$ ), then these $16 S$ rRNA related short reads were de novo assembled for longer 16S rRNA contigs using MIRA with the default parameters (Chevreux et al., 2004). Contigs longer than 400 bps were aligned with reference sequences via the Greengenes Nearest Alignment Space Termination (NAST) Alignment Tool (DeSantis et al., 2006), and the phylogenetic tree was constructed in ARB software with Maximum Likelihood method after the chimera checking (Ludwig et al., 2004).

Analysis of pHMO operon structure and population variability. Hydrocarbon monooxygenase operon structure was analysed on sequence similarity of three subunits $(A, B$ and $\mathrm{C}$ ). Identity values for protein sequence of pHMO were calculated by LALIGN (Huang and Miller, 1991, http:// embnet.vital-it.ch/software/LALIGN_form.html). To identify single-nucleotide polymorphisms (SNPs), two contigs with complete $\mathrm{pMMO}$ operons from the metatranscriptome assembly were realigned with the original Illumina short reads datasets by Bowtie (Langmead et al., 2009) using paired-end model and zero mismatches, and then visualized by Integrated Genome Viewer (Robinson et al., 2011) to confirm the SNP positions.

Transcriptional activity and distribution of pHMOs. To investigate the transcriptional activity and distribution of different pHMO groups, we recruited cDNA reads to representative genes of different pHMO groups via BLAST. Following the method described previously (Lesniewski et al., 2012), the BLAST hit with highest bit score for each query was used to calculate the number of reads recruited to each subject per dataset. In cases where short read sequences hit multiple subjects with equal bit score, scores were weighted based on number of subjects hit [score $=1 /$ (number of subjects)]. These scores were then normalized to the length of each gene fragment and total number of sequences in each database. To avoid false hits to $\mathrm{pHMO}$ sequences from AMO sequences, which are abundant in GB metatranscriptomic datasets (Baker et al., 2012), we constructed a database including both $\mathrm{pHMO}$ and $\mathrm{AMO}$-coding gene sequences and discarded sequences with best hits to AMO. Sequences related to pHMOs with BLAST bit score $>50$ (subunit $A$ ) and $>65$ (subunits $B$ and $C$ ) were assigned as pHMOs. Relative abundance of $16 \mathrm{~S}$ rRNA of pHMOs-related bacteria was also calculated using the same normalization procedure with the BLAST bit score $>50$ and percentage identity $>99 \%$. To 
further understand the presence and distribution of these pHMOs in other marine environments, we also searched $\mathrm{NCBI}$ and Integrated Microbial Genomes (IMG) databases for sequences similar to PmoA.

Data deposition. This Whole Genome Shotgun project has been deposited at DDBJ/EMBL/GenBank under the accession AJXC00000000. The version described in this paper is the first version, AJXC01000000. Transcript sequences are available at the NCBI sequence read archive under the accession SRP007999. Annotated gene and protein sequences are available from DOE JGI-IMG under Taxon Object ID: 2061766003.

\section{Acknowledgements}

This work is funded by the Gordon and Betty Moore Foundation through Grant GBMF2609 to GJD, the National Science Foundation (OCE 1029242) and the University of Michigan Center for Computational Medicine Pilot Research Grant Program. Dr Cody Sheik, Karthik Anantharaman, Daniel Marcus, Alex Voorhies and Dr Daniel Reed provided helpful comments and revisions to the manuscript. We thank Professor Victoria Orphan and Dr Patty Tavormina for providing reference sequences and valuable input. DNA sequencing was conducted in the laboratory of Stephan Schuster at Penn State University (454) and at The University of Michigan DNA Sequencing Core (Illumina).

\section{References}

Abascal, F., Zardoya, R., and Posada, D. (2005) ProtTest: selection of best-fit models of protein evolution. Bioinformatics 21: 2104-2105.

Arp, D.J., Chain, P.S.G., and Klotz, M.G. (2007) The impact of genome analyses on our understanding of ammoniaoxidizing bacteria. Annu Rev Microbiol 61: 503-528.

Baani, M., and Liesack, W. (2008) Two isozymes of particulate methane monooxygenase with different methane oxidation kinetics are found in Methylocystis sp. strain SC2. Proc Natl Acad Sci USA 105: 10203-10208.

Baelum, J., Borglin, S., Chakraborty, R., Fortney, J.L., Lamendella, R., Mason, O.U., et al. (2012) Deep-sea bacteria enriched by oil and dispersant from the Deepwater Horizon spill. Environ Microbiol 14: 2405-2416.

Baker, B.J., Lesniewski, R.A., and Dick, G.J. (2012) Genome-enabled transcriptomics reveals archaeal populations that drive nitrification in deep-sea hydrothermal plume. ISME J 6: 2269-2279.

Baker, B.J., Sheik, C.S., Taylor, C.A., Jain, S., Bhasi, A., Cavalcoli, J.D., et al. (2013) Community transcriptomic assembly reveals microbes that contribute to deep-sea carbon and nitrogen cycling. ISME J. doi: 10.1038/ ismej.2013.85. (in press).

Balasubramanian, R., Smith, S.M., Rawat, S., Yatsunyk, L.A., Stemmler, T.L., and Rosenzweig, A.C. (2010) Oxidation of methane by a biological dicopper centre. Nature 465: 115119.

Beaulieu, S.E. (2010) InterRidge global database of active submarine hydrothermal vent fields: prepared for InterRidge, Version 2.0. World Wide Web electronic publication [WWW document]. URL http://www.interridge. org/IRvents.

van Beilen, J.B., and Funhoff, E.G. (2007) Alkane hydroxylases involved in microbial alkane degradation. Appl Microbiol Biotechnol 74: 13-21.

van Beilen, J.B., Li, Z., Duetz, W.A., Smits, T.H.M., and Witholt, B. (2003) Diversity of alkane hydroxylase systems in the environment. Oil Gas Sci Technol 58: 427-440.

Berger, S.A., Krompaß, D., and Stamatakis, A. (2011) Performance, accuracy and web-server for evolutionary placement of short sequence reads under maximumlikelihood. Syst Biol 60: 291-302.

Berube, P.M., and Stahl, D.A. (2012) The divergent AmoC3 subunit of ammonia monooxygenase functions as part of a stress response system in Nitrosomonas europaea. $J$ Bacteriol 194: 3448-3456.

Biddle, J.F., Cardman, Z., Mendlovitz, H., Albert, D.B., Lloyd, K.G., Boetius, A., et al. (2011) Anaerobic oxidation of methane at different temperature regimes in Guaymas Basin hydrothermal sediments. ISME J 5: 1-14.

Boden, R., Cunliffe, M., Scanlan, J., Moussard, H., Kits, K.D., Klotz, M.G., et al. (2011) Complete genome sequence of the aerobic marine methanotroph Methylomonas methanica MC09. J Bacteriol 193: 7001-7002.

Campbell, K.A. (2006) Hydrocarbon seep and hydrothermal vent paleoenvironments and paleontology: past developments and future research directions. Palaeogeogr Palaeoclimatol Palaeoecol 232: 362-407.

Capella-Gutierrez, S., Silla-Martinez, J.M., and Gabaldon, T. (2009) TrimAl: a tool for automated alignment trimming in large-scale phylogenetic analyses. Bioinformatics 25: 1972-1973.

Chen, Y., Crombie, A., Rahman, M.T., Dedysh, S.N., Liesack, W., Stott, M.B., et al. (2010) Complete genome sequence of the aerobic facultative methanotroph Methylocella silvestris BL2. J Bacteriol 192: 3840-3841.

Chevreux, B., Pfisterer, T., Drescher, B., Driesel, A.J., Muller, W.E.G., Wetter, T., et al. (2004) Using the miraEST assembler for reliable and automated mRNA transcript assembly and SNP detection in sequenced ESTs. Genome Res 14: 1147-1159.

Chistoserdova, L. (2011) Modularity of methylotrophy, revisited. Environ Microbiol 13: 2603-2622.

Coleman, N.V., Yau, S., Wilson, N.L., Nolan, L.M., Migocki, M.D., Ly, M.A., et al. (2011) Untangling the multiple monooxygenases of Mycobacterium chubuense strain NBB4, a versatile hydrocarbon degrader. Environ Microbiol 3: 297-307.

Coleman, N.V., Le, N.B., Ly, M.A., Ogawa, H.E., McCarl, V., Wilson, N.L., et al. (2012) Hydrocarbon monooxygenase in Mycobacterium: recombinant expression of a member of the ammonia monooxygenase superfamily. ISME J 6: 171182.

Costello, A.M., and Lidstrom, M.E. (1999) Molecular characterization of functional and phylogenetic genes from natural populations of methanotrophs in lake sediments. Appl Environ Microbiol 65: 5066-5074.

Crépeau, V., Cambon Bonavita, M.A., Lesongeur, F., Randrianalivelo, H., Sarradin, P.M., Sarrazin, J., et al. (2011) Diversity and function in microbial mats from the 
Lucky Strike hydrothermal vent field. FEMS Microbiol Ecol 76: 524-540.

DeSantis, T.Z., Hugenholtz, P., Jr, Keller, K., Brodie, E.L., Larsen, N., Piceno, Y.M., et al. (2006) NAST: a multiple sequence alignment server for comparative analysis of 16S rRNA genes. Nucleic Acids Res 34: W394-W399.

Dick, G.J., and Tebo, B.M. (2010) Microbial diversity and biogeochemistry of the Guaymas Basin deep-sea hydrothermal plume. Environ Microbiol 12: 1334-1347.

Dick, G.J., Clement, B.G., Webb, S.M., Fodrie, F.J., Bargar, J.R., and Tebo, B.M. (2009) Enzymatic microbial Mn(II) oxidation and $\mathrm{Mn}$ biooxide production in the Guaymas Basin deep-sea hydrothermal plume. Geochim Cosmochim Acta 73: 6517-6530.

Dunfield, P.F., Yimga, M.T., Dedysh, S.N., Berger, U., Liesack, W., and Heyer, J. (2002) Isolation of a Methylocystis strain containing a novel pmoA-like gene. FEMS Microbiol Ecol 41: 17-26.

Dunfield, P.F., Yuryev, A., Senin, P., Smirnova, A.V., Stott, M.B., Hou, S., et al. (2007) Methane oxidation by an extremely acidophilic bacterium of the phylum Verrucomicrobia. Nature 450: 879-882.

Duperron, S., Sibuet, M., MacGregor, B.J., Kuypers, M.M., Fisher, C.R., and Dubilier, N. (2007) Diversity, relative abundance and metabolic potential of bacterial endosymbionts in three Bathymodiolus mussel species from cold seeps in the Gulf of Mexico. Environ Microbio/ 9: 1423-1438.

Elsaied, H.E., Hayashi, T., and Naganuma, T. (2004) Molecular analysis of deep-sea hydrothermal vent aerobic methanotrophs by targeting genes of $16 \mathrm{~S}$ rRNA and particulate methane monooxygenase. Mar Biotechnol 6: 503509.

Erikstad, H.A., Jensen, S., Keen, T.J., and Birkeland, N.K. (2012) Differential expression of particulate methane monooxygenase genes in the verrucomicrobial methanotroph 'Methylacidiphilum kamchatkense' Kam1. Extremophiles 16: 405-409.

Ettwig, K.F., Butler, M.K., Le Paslier, D., Pelletier, E., Mangenot, S., Kuypers, M.M., et al. (2010) Nitrite-driven anaerobic methane oxidation by oxygenic bacteria. Nature 464: 543-548.

Francis, C.A., Roberts, K.J., Beman, J.M., Santoro, A.E., and Oakley, B.B. (2005) Ubiquity and diversity of ammonia-oxidizing archaea in water columns and sediments of the ocean. Proc Natl Acad Sci USA 102: 14683-14688.

Frias-Lopez, J., Shi, Y., Tyson, G.W., Coleman, M.L., Schuster, S.C., Chisholm, S.W., et al. (2008) Microbial community gene expression in ocean surface waters. Proc Natl Acad Sci USA 105: 3805-3810.

Gilbert, J.A., and Dupont, C.L. (2011) Microbial metagenomics: beyond the genome. Ann Rev Mar Sci 3: 347-371.

Gilbert, J.A., Field, D., Huang, Y., Edwards, R., Li, W.Z., Gilna, P., et al. (2008) Detection of large numbers of novel sequences in the metatranscriptomes of complex marine microbial communities. PLoS One 3: e3042.

Hamamura, N., and Arp, D.J. (2000) Isolation and characterization of alkane-utilizing Nocardioides sp. strain CF8. FEMS Microbiol Lett 186: 21-26.
Hamamura, N., Storfa, R.T., Semprini, L., and Arp, D.J. (1999) Diversity in butane monooxygenases among butane-grown bacteria. Appl Environ Microbiol 65: 45864593.

Hamamura, N., Yeager, C.M., and Arp, D.J. (2001) Two distinct monooxygenases for alkane oxidation in Nocardioides sp. strain CF8. Appl Environ Microbiol 67: 4992-4998.

Hanson, R.S., and Hanson, T.E. (1996) Methanotrophic bacteria. Microbiol Rev 60: 439-471.

Havelsrud, O.E., Haverkamp, T.H., Kristensen, T., Jakobsen, K.S., and Rike, A.G. (2011) A metagenomic study of methanotrophic microorganisms in Coal Oil Point seep sediments. BMC Microbiol 11: 221.

Hayashi, T., Obata, H., Gamo, T., Sano, Y., and Naganuma, T. (2007) Distribution and phylogenetic characteristics of the genes encoding enzymes relevant to methane oxidation in oxygen minimum zones of the eastern Pacific Ocean. J Environ Sci 1: 275-284.

Hou, S., Makarova, K.S., Saw, J.H., Senin, P., Ly, B.V., Zhou, Z., et al. (2008) Complete genome sequence of the extremely acidophilic methanotroph isolate V4, Methylacidiphilum infernorum, a representative of the bacterial phylum Verrucomicrobia. Biol Direct 3: 26.

Huang, X.Q., and Miller, W. (1991) A time-efficient, linearspace local similarity algorithm. Adv Appl Math 12: 337357.

Inagaki, F., Tsunogai, U., Suzuki, M., Kosaka, A., Machiyama, H., Takai, K., et al. (2004) Characterization of C1metabolizing prokaryotic communities in methane seep habitats at the Kuroshima Knoll, southern Ryukyu Arc, by analyzing pmoA, mmoX, mxaF, mcrA, and 16S rRNA genes. Appl Environ Microbiol 70: 7445-7455.

Kessler, J.D., Valentine, D.L., Redmond, M.C., Du, M., Chan, E.W., Mendes, S.D., et al. (2011) A persistent oxygen anomaly reveals the fate of spilled methane in the deep Gulf of Mexico. Science 331: 312-315.

Könneke, M., Bernhard, A.E., Torre, J.R., Walker, C.B., Waterbury, J.B., and Stahl, D.A. (2005) Isolation of an autotrophic ammonia-oxidizing marine archaeon. Nature 437: 543-546.

Lam, P. (2004) Microbial ammonia oxidation in deep-sea hydrothermal plumes. PhD Thesis. Hawaii, USA: University of Hawaii.

Langmead, B., Trapnell, C., Pop, M., and Salzberg, S.L. (2009) Ultrafast and memory-efficient alignment of short DNA sequences to the human genome. Genome Biol 10: R25.

Lesniewski, R.A., Jain, S., Anantharaman, K., Schloss, P.D., and Dick, G.J. (2012) The metatranscriptome of a deepsea hydrothermal plume is dominated by water column methanotrophs and chemolithotrophs. ISME J 6: 22572268.

Lieberman, R.L., and Rosenzweig, A.C. (2005) Crystal structure of a membrane-bound metalloenzyme that catalyses the biological oxidation of methane. Nature 434: 177-182.

Ludwig, W., Strunk, O., Westram, R., Richter, L., Meier, H., Yadhukumar, et al. (2004) ARB: a software environment for sequence data. Nucleic Acids Res 32: 1363-1371.

Lüke, C., and Frenzel, P. (2011) Potential of pmoA amplicon pyrosequencing for methanotroph diversity studies. Appl Environ Microbiol 77: 6305-6309. 
McCollom, T. (2008) Observational, experimental, and theoretical constraints on carbon cycling in mid-ocean ridge hydrothermal systems. In Geophysical Monograph Series. Vol. 178. Lowell, R.P., Seewald, J.S., Metaxas, A., and Perfit, M. (eds). Washington, DC, USA: AGU, pp. 193-213.

McDonald, I.R., Bodrossy, L., Chen, Y., and Murrell, J.C. (2008) Molecular ecology techniques for the study of aerobic methanotrophs. Appl Environ Microbiol 74: 13051315.

Mason, O.U., Hazen, T.C., Borglin, S., Chain, P., Dubinsky, E.A., Fortney, J.L., et al. (2012) Metagenome, metatranscriptome and single-cell sequencing reveal microbial response to Deepwater Horizon oil spill. ISME J 6: $1715-1727$.

Milkov, A.V., Sassen, R., Apanasovich, T.V., and Dadashev, F.G. (2003) Global gas flux from mud volcanoes: a significant source of fossil methane in the atmosphere and the ocean. Geophys Res Lett 30: 1037. doi:10.1029/ $2002 G L 016358$.

Muyzer, G., and van der Kraan, G.M. (2008) Bacteria from hydrocarbon seep areas growing on short-chain alkanes. Trends Microbiol 16: 138-141.

Nercessian, O., Fouquet, Y., Pierre, C., Prieur, D., and Jeanthon, C. (2005) Diversity of Bacteria and Archaea associated with a carbonate-rich metalliferous sediment sample from the Rainbow vent field on the Mid-Atlantic Ridge. Environ Microbiol 7: 698-714.

Norton, J.M., Alzerreca, J.J., Suwa, Y., and Klotz, M.G. (2002) Diversity of ammonia monooxygenase operon in autotrophic ammonia-oxidizing bacteria. Arch Microbiol 177: $139-149$

Pol, A., Heijmans, K., Harhangi, H.R., Tedesco, D., Jetten, M.S., and Op den Camp, H.J. (2007) Methanotrophy below pH 1 by a new Verrucomicrobia species. Nature 450: $874-$ 878.

Raggi, L., Schubtz, F., Hinrichs, K.U., Dubilier, N., and Petersen, J.M. (2012) Bacterial symbionts of Bathymodiolus mussels and Escarpia tubeworms from Chapopote, an asphalt seep in the southern Gulf of Mexico. Environ Microbiol. doi:10.1111/1462-2920.12051 (in press).

Redmond, M.C., Valentine, D.L., and Sessions, A.L. (2010) Identification of novel methane-, ethane-, and propaneoxidizing bacteria at marine hydrocarbon seeps by stable isotope probing. Appl Environ Microbiol 76: 6412-6422.

Reed, A.J., Dorn, R., van Dover, C.L., Lutz, R.A., and Vetriani, C. (2009) Phylogenetic diversity of methanogenic, sulfate-reducing and methanotrophic prokaryotes from deep-sea hydrothermal vents and cold seeps. Deep-Sea Res Part // 56: 1665-1674.

Robinson, J.T., Thorvaldsdottir, H., Winckler, W., Guttman, M., Lander, E.S., Getz, G., et al. (2011) Integrative genomics viewer. Nat Biotechnol 29: 24-26.

Sayavedra-Soto, L.A., Hamamura, N., Liu, C.W., Kimbrel, J.A., Chang, J.H., and Arp, D.J. (2011) The membraneassociated monooxygenase in the butane-oxidizing Grampositive bacterium Nocardioides sp. strain CF8 is a novel member of the AMO/PMO family. Environ Microbiol Rep 3: 390-396.

Schloss, P.D., Westcott, S.L., Ryabin, T., Hall, J.R., Hartmann, M., Hollister, E.B., et al. (2009) Introducing mothur: open-source, platform-independent, community- supported software for describing and comparing microbial communities. Appl Environ Microbiol 75: 7537-7541.

Schulz, M.H., Zerbino, D.R., Vingron, M., and Birney, E. (2012) Oases: robust de novo RNA-seq assembly across the dynamic range of expression levels. Bioinformatics 28: 1086-1092.

Sheik, C.S., Jain, S., and Dick, G.J. (2013) Metabolic flexibility of enigmatic SAR324 revealed through metagenomics and metatranscriptomics. Environ Microbiol. doi: 10.1111/ 1462-2920.12165. (in press).

Shi, Y., Tyson, G.W., Eppley, J.M., and DeLong, E.F. (2011) Integrated metatranscriptomic and metagenomic analyses of stratified microbial assemblages in the open ocean. ISME J 5: 999-1013.

Sievers, F., Wilm, A., Dineen, D., Gibson, T.J., Karplus, K., Li, W., et al. (2011) Fast, scalable generation of high-quality protein multiple sequence alignments using Clustal Omega. Mol Syst Biol 7: 539.

Spiridonova, E.M., Kuznetsov, B.B., Pimenov, N.V., and Tourova, T.P. (2006) Phylogenetic characterization of endosymbionts of the hydrothermal vent mussel Bathymodiolus azoricus by analysis of the 16S rRNA, cbbL, and pmoA genes. Microbiology 75: 694-701.

Stamatakis, A. (2006) RAxML-VI-HPC: maximum likelihoodbased phylogenetic analyses with thousands of taxa and mixed models. Bioinformatics 22: 2688-2690.

Stein, L.Y., Bringel, F., DiSpirito, A.A., Han, S., Jetten, M.S., Kalyuzhnaya, M.G., et al. (2011) Genome sequence of the methanotrophic alphaproteobacterium Methylocystis sp. strain Rockwell (ATCC 49242). J Bacteriol 193: 26682669.

Stoecker, K., Bendinger, B., Schoning, B., Nielsen, P.H., Nielsen, J.L., Baranyi, C., et al. (2006) Cohn's Crenothrix is a filamentous methane oxidizer with an unusual methane monooxygenase. Proc Natl Acad Sci USA 103: 23632367.

Stolyar, S., Costello, A.M., Peeples, T.L., and Lidstrom, M.E. (1999) Role of multiple gene copies in particulate methane monooxygenase activity in the methane-oxidizing bacterium Methylococcus capsulatus Bath. Microbiology 145: 1235-1244.

Suzuki, T., Nakamura, T., and Fuse, H. (2012) Isolation of two novel marine ethylene-assimilating bacteria, Haliea Species ETY-M and ETY-NAG, containing particulate methane monooxygenase-like genes. Microbes Environ 27: $54-60$.

Svenning, M.M., Hestnes, A.G., Wartiainen, I., Stein, L.Y., Klotz, M.G., Kalyuzhnaya, M.G., et al. (2011) Genome sequence of the Arctic methanotroph Methylobacter tundripaludum SV96. J Bacteriol 193: 6418-6419.

Swan, B.K., Martinez-Garcia, M., Preston, C.M., Sczyrba, A., Woyke, T., Lamy, D., et al. (2011) Potential for chemolithoautotrophy among ubiquitous bacteria lineages in the dark ocean. Science 333: 1296-1300.

Tavormina, P.L., Ussler, W., 3rd., and Orphan, V.J. (2008) Planktonic and sediment-associated aerobic methanotrophs in two seep systems along the North American margin. Appl Environ Microbiol 74: 398539895.

Tavormina, P.L., Ussler, W., 3rd., Joye, S.B., Harrison, B.K., and Orphan, V.J. (2010) Distributions of putative aerobic 
methanotrophs in diverse pelagic marine environments. ISME J 4: 700-710.

Tavormina, P.L., Orphan, V.J., Kalyuzhnaya, M.G., Jetten, M.S.M., and Klotz, M.G. (2011) A novel family of functional operons encoding methane/ammonia monooxygenaserelated proteins in gammaproteobacterial methanotrophs. Environ Microbiol Rep 3: 91-100.

Tavormina, P.L., Ussler, W., 3rd, Steele, J.A., Connon, S.A., Klotz, M.G., and Orphan, V.J. (2013) Abundance and distribution of diverse membrane-bound monooxygenase (Cu-MMO) genes within the Costa Rica oxygen minimum zone. Environ Microbiol Rep 3: 414-423. doi:10.1111/ 1758-2229.12025.

Teske, A., Hinrichs, K.U., Edgcomb, V., de Vera Gomez, A., Kysela, D., Sylva, S.P., et al. (2002) Microbial diversity of hydrothermal sediments in the Guaymas Basin: evidence for anaerobic methanotrophic communities. Appl Environ Microbiol 68: 1994-2007.

Tourna, M., Stieglmeier, M., Spang, A., Konneke, M., Schintlmeister, A., Urich, T., et al. (2011) Nitrososphaera viennensis, an ammonia oxidizing archaeon from soil. Proc Natl Acad Sci USA 108: 8420-8425.

Valentine, D.L. (2010) Measure methane to quantify the oil spill. Nature 465: 421.

Valentine, D.L. (2011) Emerging topics in marine methane biogeochemistry. Ann Rev Mar Sci 3: 147-171.

Valentine, D.L., Kessler, J.D., Redmond, M.C., Mendes, S.D., Heintz, M.B., Farwell, C., et al. (2010) Propane respiration jump-starts microbial response to a deep oil spill. Science 330: 208-211.

Vondamm, K.L., Edmond, J.M., Measures, C.I., and Grant, B. (1985) Chemistry of submarine hydrothermal solutions at Guaymas Basin, Gulf of California. Geochim Cosmochim Acta 49: 2221-2237.

Ward, N., Larsen, O., Sakwa, J., Bruseth, L., Khouri, H., Durkin, A.S., et al. (2004) Genomic insights into methanotrophy: the complete genome sequence of Methylococcus capsulatus (Bath). PLoS Biol 2: e303.

Wasmund, K., Kurtboke, D.I., Burns, K.A., and Bourne, D.G. (2009) Microbial diversity in sediments associated with a shallow methane seep in the tropical Timor Sea of Australia reveals a novel aerobic methanotroph diversity. FEMS Microbiol Ecol 68: 142-151.

Welhan, J.A., and Lupton, J.E. (1987) Light hydrocarbon gases in Guaymas Basin hydrothermal fluids: thermogenic versus abiogenic orign. Am Assoc Pet Geol Bull 71: 215223.

Yan, T., Ye, Q., Zhou, J., and Zhang, C.L. (2006) Diversity of functional genes for methanotrophs in sediments associated with gas hydrates and hydrocarbon seeps in the Gulf of Mexico. FEMS Microbiol Ecol 57: 251-259.

Zbinden, M., Shillito, B., Le Bris, N., De Villardi de Montlaur, C., Roussel, E., Guyot, F., et al. (2008) New insights on the metabolic diversity among the epibiotic microbial community of the hydrothermal shrimp Rimicaris exoculata. $J$ Expe Mar Biol Ecol 359: 131-140.

Zerbino, D.R., and Birney, E. (2008) Velvet: algorithms for de novo short read assembly using de Bruijn graphs. Genome Res 18: 821-829.

\section{Supporting information}

Additional Supporting Information may be found in the online version of this article at the publisher's web-site:

Fig. S1. Phylogenetic relationship of pHMOs based on subunit B.

Fig. S2. Phylogenetic relationship of pHMOs based on subunit $\mathrm{C}$.

Fig. S3. Comparison of the metal-binding sites for pHMOs identified in this study and other representative CuMMOs. The + indicates the carboxylate side-chain residues postulated to coordinate a di-iron center; \# indicates the variable metal site of subunits $A$ and $C$; \& indicates the ligands to mononuclear copper; * indicates the subunit B dinuclear copper site. Colored shading indicates putative substrate of each enzyme: light blue is methane, dark blue is ethylene, pink and green are ethane and $\mathrm{C}_{2}-\mathrm{C}_{4}$ alkanes, respectively. ${ }^{1}$ these sequences are incomplete; dashes shows missing data.

Fig. S4. Sequence variation of Deep sea-2/PS-80 and Deep sea-3/OPU3 pMMO operons and corresponding variation in their amino acid sequences.

Fig. S5. Normalized transcript abundance for $16 \mathrm{~S}$ rRNA sequences of different pHMO groups in plume and background samples. The normalized numbers were divided to the total number of transcript reads from plume and background samples.

Table S1. Summary of samples and sequencing in this study, after Lesniewski et al. 2012.

Table S2. Sequence identities (amino acid \%) of three subunits of pHMO identified in this study to CuMMOs contained in type strains.

Table S3. Distribution of different pHMO groups in diverse pelagic marine environments based on NCBI clone sequence survey.

Table S4. Distribution of different pHMO groups in diverse marine environments based on metagenomes and metatranscriptomes survey. 